\title{
Venice: the geometry of the origins
}

\section{Luigi Calzavara}

Published online: 4 March 2015

(c) Centro P.RI.ST.EM, Università Commerciale Luigi Bocconi 2015 shapes, emerge from the rooftops to dominate the city. The observation of these traces, which are perfectly measurable topographical polygons, makes it possible to identify and describe parts of the original layout of the city. Above all, in a city that is a labyrinth, the targeted location of the cells of the bell towers-veritable elevated platforms of information-satisfy the vital need to communicate, by sight and in ordered form, between points within the city. The collection and exchange of information provided the basis for all decisions [2].

\section{The "good" shape}

For centuries the inland region of the upper Adriatic, from Rimini to Aquileia, was one large construction site: modifications, overthrows, fortifications. Still today maps show us precise and distinctive traces of regular geometry, repetitive measurements, and in general large traces of right angles. In the landscape the network of roadways is determinant because the routes condition the economy and the way of life. Thus, precisely in everyday life, opposite but converging needs of modularity, integration and order have privileged the construction of orthogonal forms. These, in fact, have their origins in the choice of natural economy and have dictated those practical mathematical aids that help us to live.

This is certainly the case of the right triangle. This shape has the fundamental advantage of simplicity of construction: it depends on a single variable: of the three angles, one is right, and the others are obviously complementary: $90^{\circ}, 90^{\circ}-\alpha, \alpha$. Right triangles have been studied since antiquity with great interest. They can be constructed using whole numbers and on the basis of the Pythagorean theorem. Among these triangles the easiest to manage is also 


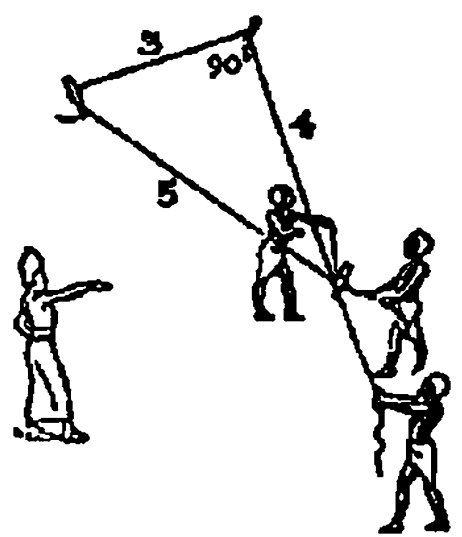

Fig. 1 Practical construction of a geometrical shape with sides measuring whole numbers. This is the case of the first Pythagorean triangle

constructed on the basis of the ancient sexagesimal numeration: its sides are in proportion to the numbers $3,4,5$; the area is 6 ; the perimeter is 12 . This precise triangle was also the basis of Egyptian geometry. For example, the Kahun Papyrus (beginning of the second millennium B.C.) describes a particular right triangle that could be constructed using only a rope subdivided into twelve equal parts by knots (Fig. 1).

The loop of rope, held by three men at the third knot (3), at the seventh $(3+4)$ and at the twelfth $(3+4+5)$ naturally assumed the shape of the right triangle with sides of 3,4 and 5. The loop itself was knotted from the very beginning to form that shape [7], which corresponds to the well-known Pythagorean equation $3^{2}+4^{2}=5^{2}$ There is more, however: this particular loop of rope is still today the tool used by our master masons when they need a practical way to lay out the right angles for a house. Above all, this is a model example of least action [6] that connects mathematics to geometry: an indispensable tool for the builder, like a plumb line. To summarise, the loop of rope stretched in this way represents the concrete model of the first right triangle whose sides are whole numbers, that is, Pythagorean, and the lengths of its sides $(3,4,5)$ form the first Pythagorean triad.

\section{Bell towers: primitive sites and topographical fixed points}

The bell tower of Saint Mark's, which collapsed in 1902, was immediately rebuilt on the same site, "where it was and how it was". This decision on the part of the city's administration, when considered carefully, might be due not somuch to the ownership of the site and the event's symbolic significance, and thus tied to everyday life, but above all to problems that endured over time: practical, constructive, economic. In Venice, immobility is not a social choice, but an economic necessity. In fact, the city rose on groups of piles sunk into a marshy terrain. As a consequence bell towers, with their heavy concentrated loads, rest on foundations that are as laborious to build as they are costly; the foundations might be more costly than the towers they support. Over time, when structural settling occurred, it was always preferable to reinforce and re-dimension the structures, particularly the foundations of the ancient guard towers or bell towers. The marshes did not permit their being moved. Thus, in this phase of research and for economic reasons, the bell towers were considered constructive pointed fixed over time: primitive sites that have given rise to the community organised in the lagoon, and that, in our opinion, were constructed before-never after-the churches next to them. The bell towers, in fact are not clearly documented in the historic archives, and were perhaps erected precisely on the foundations of ancient guard towers. On the basis of this hypothesis have been evaluated the fifty bell towers connected to the oldest churches in the city, those already founded by the eleventh century [5].

These bell towers occupy very precise places in the Cartesian network of the official cartography of the city: they are easily measurable topographical fixed points [8]. Thus it is possible to evaluate the topographical relationships between them. This is the scientific foundation of this present paper.

\section{Bell towers as the vertices of quasi-Pythagorean triangles}

We can see that the fifty bell towers of the oldest Venetian churches, already operating in the eleventh century, seem to be precisely located within the city: a genuine distribution. In fact, almost all the bell towers are vertices of "quasi-Pythagorean triangles", that is, triangles in which the smallest angle is greater than $9^{\circ}$ and the largest angle tends to the right angle with a programmed tolerance, less than $1 / 8$ of a hexadecimal degree. Only minimum tolerances can render the shapes statistically significant.

It is precisely in this way that we observed-we saw emerge-the geometric grid of 61 triangular cells characterised by at least one common vertex. A fundamental fact is that the position of each bell tower, except for two, seems to depend on the position of others. In this way, the bell towers can form a system, that is, a common aim. Among themselves, perhaps, the topographical information runs intentionally-in a constructive form-to realise a precise project, in the same way that electric current runs through a network of urban illumination. 
This grid of particular triangles forms the basis of the geometry of Venice. The grid itself, in fact, makes evident two fundamental distributive characteristics: on one hand the singular order of these shapes, which turn out to be always connected to each other, and on the other hand the frequency of the shapes themselves, particularly significant in the area in the centre of the city, which is the oldest. This paves the way to a statistical evaluation that, for the sake of simplicity and clarity, limits the analysis in time and in space: the bell towers that are connected to the first churches of the city-operative by the eleventh century-and rising within the well-defined area of the Rialto Bridge. The statistical experiment turns out to refute the hypothesis of a chance distribution of bell towers, and supports the hypothesis of the existence of a pre-determined and systematic geometrical scheme [3].

\section{The great triangle: the survey}

The statistical evaluation, while very significant in itself, is only the enunciation of a constructive process. Now, in order to ascertain the methods, we also wish to establish the reliablity of the values found: their effectiveness in making evident the constructive technique used (Fig. 2).

Thus, among the dense grid of quasi-Pythagorean triangles that cover Venice, let us consider the triangular ring of maximum surface that effectively extends over the entire city and connects with two vertices of the same grid. This is number 42: the great triangle shown in Fig. 2 that, in addition to being an almost exactly right triangle $\left(89.95^{\circ}\right)$, expresses, through the quality of the numbers shown in the table, the historical origins of the layout.

Now let us look around a little. Vertex $\mathrm{C}$ of the largest angle is precisely the bell tower of the island of San Pietro in of Castello: the historic site of the first organised defense of the lagoon. On this island, today the site of the cathedral consecrated to St. Peter, and above all in the particular bell tower, the only one in the city in white stone, is situated the origin of the great triangle, the topological foundation of this work. This is, obviously, a virtual triangle, but one that is perfectly measurable, and which connects the bell tower of S. Pietro in Castello (C) with that of the church of SS. Donato e Maria (B) to the north, on the island of Murano, and that of S. Nicolò dei Mendicoli (A) to the west, towards land. Thus, on the basis of well-defined relationships, it is possible to hypothesise a very precise topographical project based on the fixed points A, B and C, vertices of the triangle; this is a presumed layout. The data has been ordered in a table and in what follows will be compared to what has been surveyed on the ground in order to evaluate the deviation between design and reality.

\section{The great triangle: the topographical design}

Table 1 presents a numerical synthesis that summarises and harmonises the dates and practical methods of the ancient design of the great triangle. The table itself, from left to right and line after line, shows the Roman measurements of the presumed design, and in particular, the specific measurements of the sides and perimeter. For each entry it is also easy to evaluate the deviation between the theoretical measurements in meters of the sides themselves (column*) and those surveyed in the cartography (column **). The minimal deviations lend support to the hypothesis.

\section{The great triangle: the unit of measure}

The unit of measure used in the layout thus appears to be the Roman foot, equal to $29.53 \mathrm{~cm}$. This elementary measurement was derived by dividing the surveyed perimeter of the great triangle $(10,206.387 \mathrm{~m})$ by the unit of measure $(34,560$ $\mathrm{ft}$ ) foreseen in our presumed layout. From this emerges a value of $29.53 \mathrm{~cm}$, which is smaller than the ancient Roman foot $(29.73 \mathrm{~cm})$, but larger than the one in use in the third century A.D. (29.42 cm). In fact, the measure is very close to that used normally in the Po River plane $(29.57 \mathrm{~cm})$.

More in general, observing the surveyed measurements of the sides of the great triangle, we see that the hypotenuse AB $(4,250.861 \mathrm{~m})$ can be divided into six segments of $708.477 \mathrm{~m}$-approximately equal to 20 actaeand to 2,400 feet of $29.53 \mathrm{~cm}$. This measure is very significant, because it coincides with the average value of the side of a Roman centuria [4], which varies from 705 to $710 \mathrm{~m}$.

Here then are the supporting factors: the almost homogeneous ratios between the measurements of the sides and the values of the first Pythagorean triad $(3,4,5)$, but above all, the measurements of the sides. These are in fact precise multiples_with minimum deviations - of well-known Roman units of measurement: the actus, pertica, foot. All of this confirms the topographical solidity of our hypothesis: the great Pythagorean triangle is a model of virtual centuriation, adapted to the water of the lagoon, but always aimed at topographical control of each individual point of the surface. Thus the layout in question, by dimensions, precision and historical quality of the vertices and measurements, might also have been the first fundamental step towards the construction of the city itself.

\section{The great triangle: practical realisation in the field}

The water of the lagoon naturally favoured the layout of the great triangle. In fact, the high tides, in covering the shoals, form a perfectly flat surface with minimal friction. This 
Fig. 2 A grey dot indicates the position of a bell tower. Small numbered circles indicated the bell towers in question. In white and red almost equal lines subdivide the sides of triangle $\mathrm{ABC}$ according to Pythagorean numbers $(3,4,5)$. Dotted lines subdivide the hypotenuse $\mathrm{AB}$ into 6 equal parts; each part measures 20 actae, like the side of a Roman centuria. The points of entrance to the city appear to be coordinated with the centuriation $(\mathrm{a}, \mathrm{b}, \mathrm{c})$

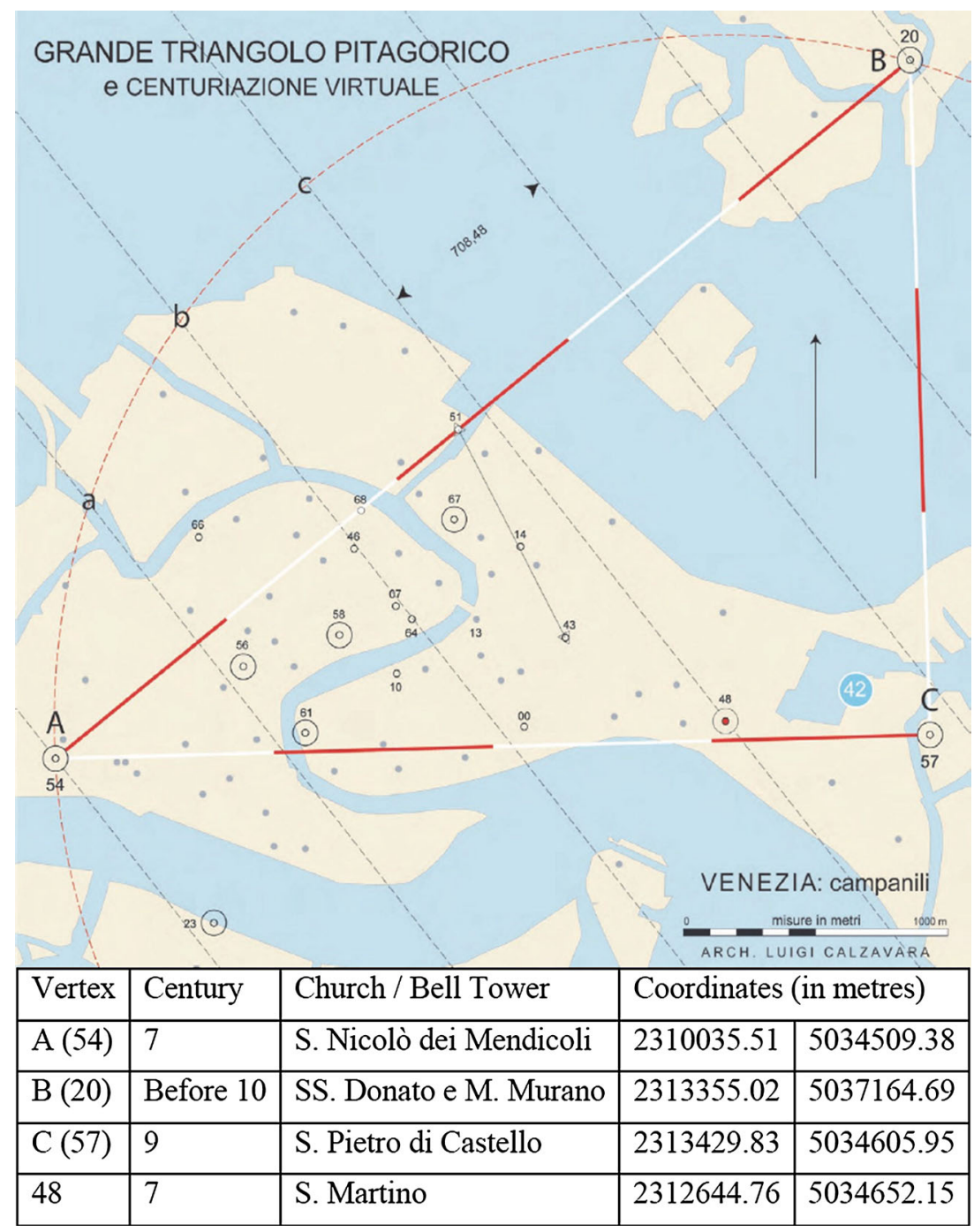

Table 1 From left, comparison between the presumed measurements $(*)$ of the sides of the great triangle and those surveyed in the field $(* *)$

\begin{tabular}{|c|c|c|c|c|c|c|c|c|}
\hline \multicolumn{7}{|l|}{ Presumed layout } & \multirow{2}{*}{$\begin{array}{l}\text { Surveyed values } \\
\text { (metres)** }\end{array}$} & \multirow[t]{2}{*}{ Deviation (\%) } \\
\hline Sides & Factors & $\times 1.2$ & $\begin{array}{l}\times \mathbf{2 0} \\
\text { Actus }\end{array}$ & $\begin{array}{l}\times \mathbf{1 2} \\
\text { Pertica }\end{array}$ & $\begin{array}{l}\times \mathbf{1 0} \\
\text { Feet }\end{array}$ & $\begin{array}{l}\times \mathbf{0 . 2 9 5 3} \\
\text { Metres* }\end{array}$ & & \\
\hline $\mathrm{BC}$ & 3 & 3.6 & 72 & $\begin{array}{c}864 \\
3 \times 288\end{array}$ & 8,640 & $2,551.392$ & $2,559.833$ & 0.34 \\
\hline $\mathrm{CA}$ & 4 & 4.8 & 96 & $\begin{array}{l}1,152 \\
4 \times 288\end{array}$ & 11,520 & $3,401.856$ & $3,395.693$ & 0.18 \\
\hline $\mathrm{AB}$ & 5 & 6.0 & 120 & $\begin{array}{l}1,440 \\
5 \times 288\end{array}$ & 14,400 & $4,252.320$ & $4,250.861$ & 0.04 \\
\hline $\mathrm{BC}+\mathrm{CA}+\mathrm{AB}$ & 12 & 14.4 & 288 & $\begin{array}{l}3,456 \\
12 \times 288\end{array}$ & 34,560 & $1,0205.568$ & $10,206.387$ & 0.01 \\
\hline
\end{tabular}

A Roman foot, equal to $29.53 \mathrm{~cm}$, appears to be the correct unit of measurement. In italics, the assumed data; **in normal font, the data surveyed in the cartography; in bold, the Pythagorean factors, the multiples of the ancient Roman measures and the deviations 
creates the necessary conditions for working over large distances with a floating metric chain: a ring formed of wooden poles ten feet long and linked to each other by iron hooks. In this frame, and on the basis of the data shown in Table 1, the floating ring-equivalent to the perimeter of triangle $\mathrm{ABC}$ - was subdivided into 3,456 poles pre-arranged among themselves according to a precise multiple (288) of the first Pythagorean triangle:

$\mathrm{BC}=3 \times 288 ; \mathrm{CA}=4 \times 288 ; \mathrm{AB}=5 \times 288$

The localisation of the vertices was carried out-with the use of barges furnished with tow rods-exercising, in determined points (A, B, C) forces that were coordinated, targeted and divergent. Chains stretched tightly gave the layout the maximum precision; the auto-regulation was in fact the natural principle of the action. Obviously the long chain was laid out, little by little, in successive interventions that were carefully modulated: 3 poles on the small side, 4 poles on the medium side, and finally 5 in the long side. For example, during the course of the work the number of poles in the chain might have had a planned and progressive increase. At the beginning of the layout: $3 \times$ $12 ; 4 \times 12 ; 5 \times 12$, and so forth, time after time, for twenty-four successive interventions. The vertex of the large angle could have been tightly anchored into the land of fixed point $\mathrm{C}$, while the other two vertices-moveablewere placed in tension by barges, perhaps also used to stack the poles themselves before and during the operation. The problems of organisation were certainly surmountable.

\section{Visual circuits}

Obviously, an ordered placement of the cells of the bell towers facilitates visual communication and perhaps expresses the primary aim of the ancient topographical design. Now, the great grid of the sixty-one quasi-Pythagorean triangles, described earlier, allows us to discern very particular layouts. This is the case, for example, of Fig. 3, which shows five bell towers (vertices $00 ; 07 ; 10 ; 14 ; 43$ ) coordinated by no fewer than five quasi-Pythagorean triangles (in black and blue circles numbered $01 ; 03 ; 24 ; 25$; 26). Thus is delineated, in red, a first visual circuit in a pentagonal shape constituted of a well-ordered group of six quasi-isosceles triangles. This quasi-symmetrical shape is an arrow-shaped form. In effect, these are precisely the
Fig. 3 A grey point indicates the location of a bell tower. Small numbered circles indicate the bell towers in question. In black, five quasi-Pythagorean triangles are marked with white numbers in blue circles. In red, an arrow-shaped form composed of six quasi-isosceles triangles with vertices in the bell towers studied

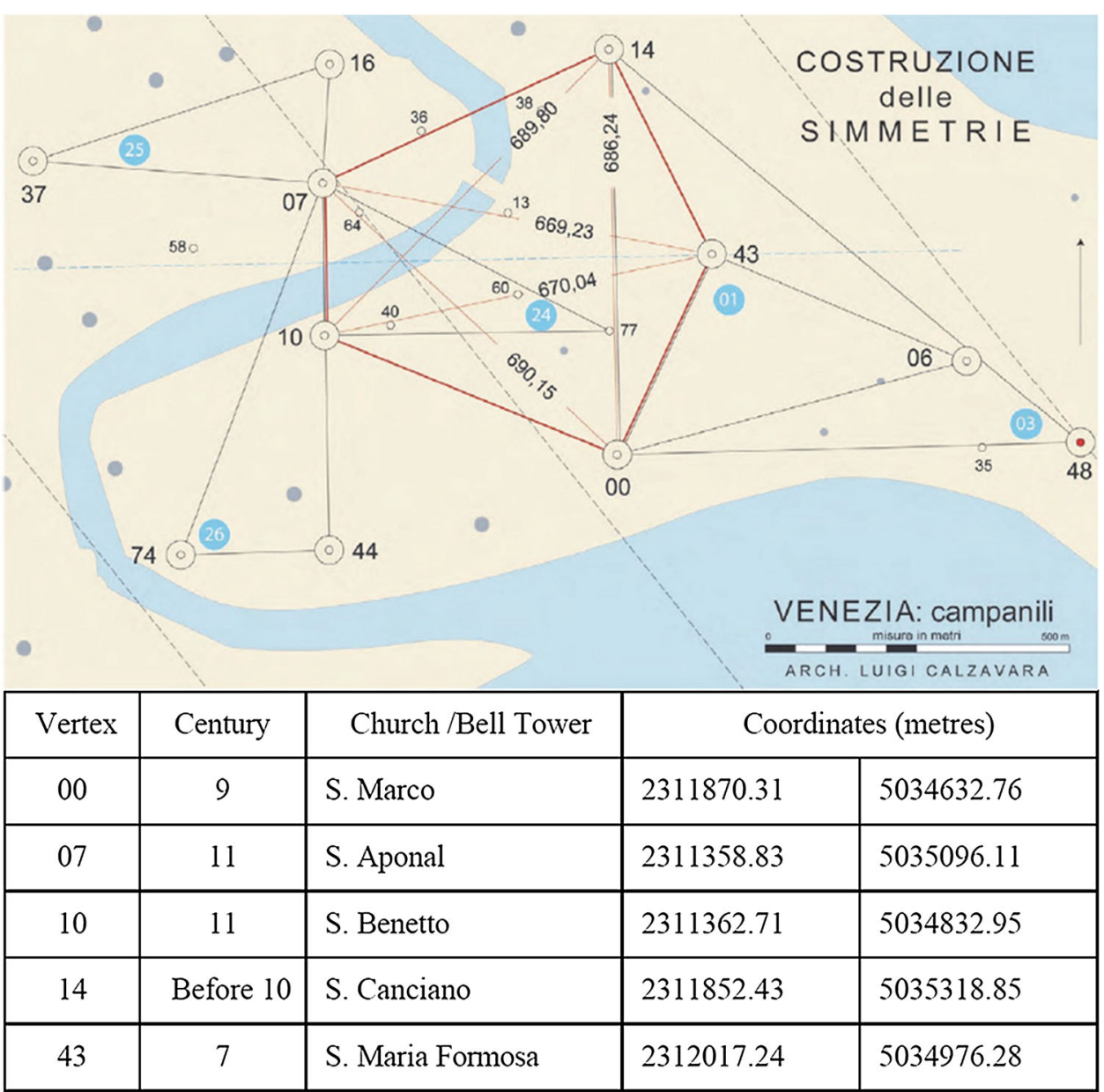


geometric characters brought to light by information theory when it studies the theoretical schema of ordered communications, two-by-two, between several sources [1].

We can clearly see the desire to optimise the reciprocal views between the information platforms placed atop the bell towers: a localisation aimed at symmetry like that of a group of friends at table for a lunch.

\section{The alignment of the bridges}

In Venice we also find order among the bridges, which were at one time drawbridges. It is precisely the bridges, a substantial and innovative element in transportation, that can be considered instruments for regulating movement, such as those located at the ports of the ancient city. Obviously, the key to controlling a drawbridge lies in its position: when down it permits human circulation, but when raise it prohibits it, allowing boats to circulate instead. This process is simple as well: a visual signal of the order, transmitted from the cell of a bell tower.

There is more, however: the location of the bridges sometimes turns out to be closely coordinated with that of the bell towers themselves. Such a case is shown in Fig. 4, which shows a distribution-collaboration-between several bridges and bell towers. Thus, we can consider the cell of the bell tower of S. Maria Formosa (43) because, as the vertex of the great red arrow-shaped form shown in Fig. 3, it shares all information in the ancient heart of the city and is a precise and repeated reference of our analysis. It will, as we will see, play a great role: fixed point of the northern sector of the city itself and point of reference of a new line of control directed, at the edges of the lagoon, up to the bell tower of the Church of the Misericordia (51). In the same way we note the particular alignment of a group of bridges: their systematic distribution from the SaccadellaMisericordiato S. Maria Formosa and from bell tower 51 to bell tower 43 (S. Maria Formosa). This is precisely the visual pathway that controls the northern entrance to the oldest nucleus of the city itself. This precise pathway goes over no fewer than five bridges (P1, P2, P3, P4, P5): a coordination founded on communication (Fig. 4). In this way, traffic was controlled by sight and with maximum ease: the work of surveillance was minimum: two look-outs from the top of the emerging structures. Furthermore, as can be seen in the maps, the bell tower of San Canciano (14) flanks the visual pathway and renders the control more reliable. The tortuous roadway that surrounds the bell tower of S. Maria Formosa (43) also has a clear strategic basis: still today, in fact, the bridges of that area turn out to be more often located along concentric arcs (a, b, c, d). All of this determines a genuine "cone of safety": four water barriers, placed in succession, can be controlled by a single visual point: the cell of the bell tower.

\section{Conclusions}

When carefully examined, the three topographical observations presented show the characters of an ordered city: a
Fig. 4 In plan, a continuous black line-see also Fig. 2connects the bell tower of the Church of theMisericordia (51) to that of S. Maria Formosa (43). Small circles mark the bridges (P1, P2, P3, P4, P5) inserted in the visual pathway. The bridges that surround $\mathrm{S}$. Maria Formosa are distributed according to concentric visual circuits $(\mathrm{a}, \mathrm{b}, \mathrm{c}, \mathrm{d})$
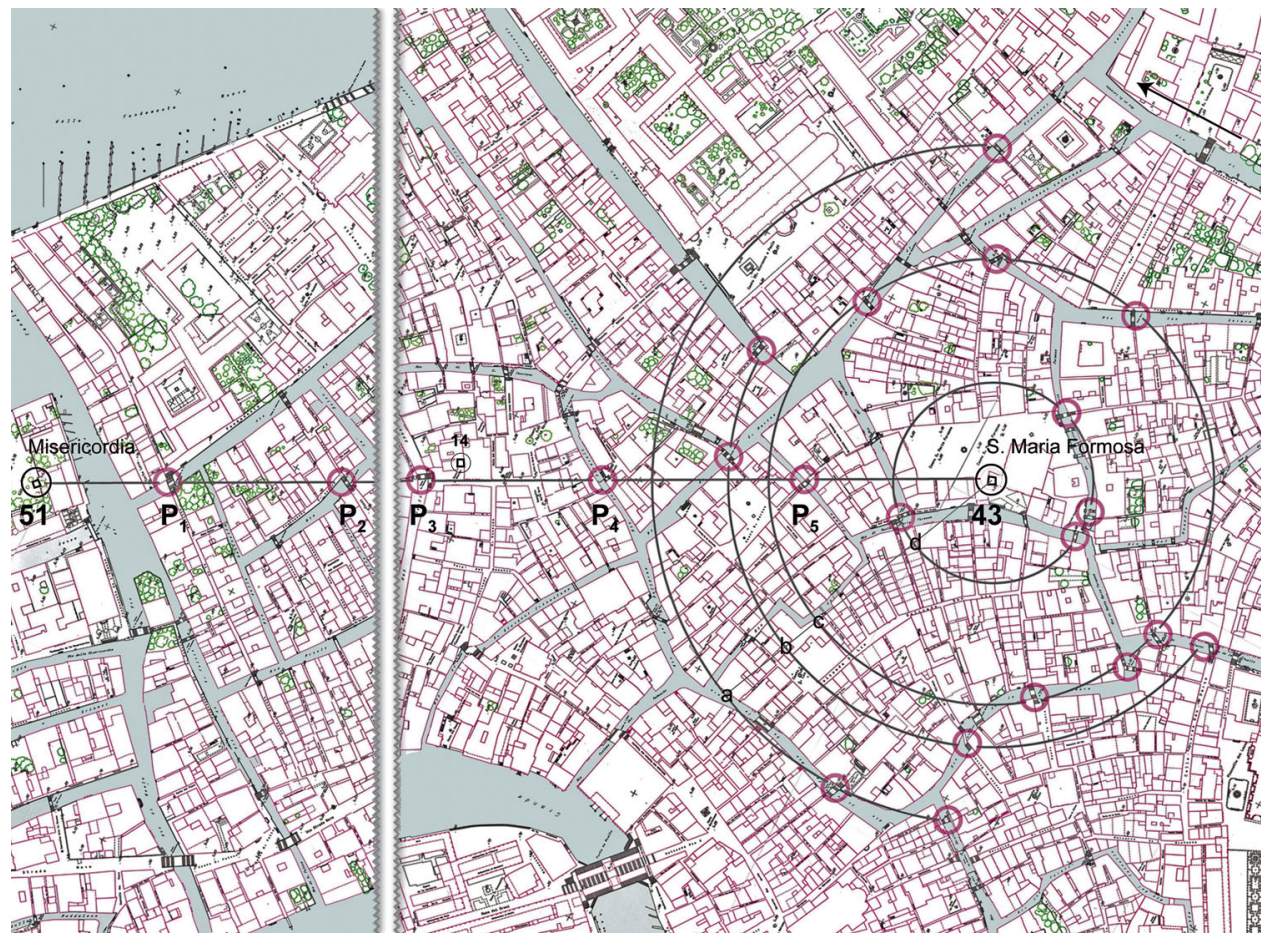
precise system of measurements based on the great Pythagorean triangle, a precise system of communication based on the symmetrical distribution of a number of bell towers, and finally a precise correlation between communication and the network of roads.

All of this is reasonable. The majestic quality of the solutions adopted appear then to prove the existence of a model aimed at satisfying, with the least effort, the new and global needs of security. Thus Venice offers a new conception of the city: a city-fortress maintained by the sea and placed at the cornerstone of the new landscape desired by Rome. Naturally, all of these considerations lead to new questions about the times and methods of development at work in the city, but also about the commitment of the designers and the headquarters of their work. A final question regards the aim: Venice as the bridgehead of an innovative Adriatic axis.

Translated from the Italian by Kim Williams.

\section{References}

1. Braffort, P.: L'intelligence artificielle. Presses universitaires de France, Paris (1968)
2. Calzavara, L.: Venezia: campanili, numeri, forme: topografia della città. Supernova, Venice (2010)

3. Calzavara, L., Brizzi, M.: The geometry of Venice: topographical observation and statistical appraisal. MetodoloskiZvezki J Stat Soc Slov 1(1), 265-275 (2004)

4. Dilke, W.: Gli Agrimensori di Roma Antica. Edagricole, Bologna (1979)

5. Dorigo, W.: Venezia Origini, vol. II. Electa, Milan (1983)

6. Hildebrandt, S., Tromba, A.: Principi di minimo. Forme ottimali in natura. Scuola Normale Superiore, Pisa (2006)

7. Hogben, L.: La matematica. Sansoni, Florence (1962)

8. Salzano, E. (ed.): Atlante di Venezia. Marsilio, Venice (1991)

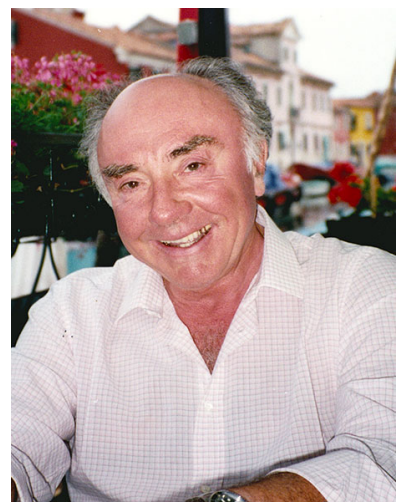

Luigi Calzavara earned his degree in architecture in Venice. He lives and works in Padua, where he was active as in practice and research in economics and civil estimates at the Istituto di OrganizzazioneAziendalein the Faculty of Engineering at the University of Padua. It was there, on 25 March 1983, that he met the teachers and researchers of the Institute on the distribution of the population centres of the Veneto, the focus of his scientific interests. 